\title{
Epidemiological Status of Lameness in horses: A Retrospective Study
}

\author{
D. P. Tank ${ }^{*}$, R. H. Bhatt, V. D. Dodia, J. V. Vadalia and N. R. Padaliya \\ Department of Veterinary Surgery \& Radiology, College of Veterinary Science \& A. H., \\ Junagadh Agricultural University, Junagadh, India \\ *Corresponding author
}

\section{A B S T R A C T}

\section{Ke y w o r d s \\ Lameness in horses, Locomotor system, Signalment \\ Article Info \\ Accepted: \\ 07 August 2020 \\ Available Online: \\ 10 September 2020}

The present entitled study was carried out to know clinical epidemiology of affections causing lameness in horses based on three years data of Veterinary Clinical Complex, College of Veterinary Science \& A. H., Junagadh Agricultural University, Junagadh. To know epidemiological status of lameness in horses, signalment and clinical details of three years (April, 2017 - March, 2020) cases were analyzed. The clinical epidemiology of 206 registered cases of lameness during last three years revealed higher incidences of lameness in less than 5 years of age group while sex wise females were more affected as compared to males. Breed wise, Kathiawari and Non-descript breeds showed more incidences of lameness while season wise distribution of cases was higher in summer. Hoof region was mostly affected followed by fetlock region while affection wise, myositis was found highest followed by laminitis during the study.

\section{Introduction}

Horses are remarkably strong animals, but their inappropriate use and design of their own body, making them highly susceptible to lameness which ultimately decreases the performance of horses (Hammarberg et al., 2016). Lameness is an abnormal stance or gait caused by either structural or functional disorders of the locomotor system (Baxter, 2011). It can be caused by trauma, nutritional deficiencies, conformational defects, managemental and environmental factors, absence of hygiene, congenital or acquired anomalies, developmental defects, infection, metabolic disturbances, circulatory and nervous disorders (Whitton, 2010). In horses, forelimbs carry $60-65 \%$ of total body weight as well as absorb the shock of landing during movement make them more susceptible to lameness. It is believed that at least $95 \%$ of lameness in the forelimbs occurs below the knee while in hindlimbs, approximately $80 \%$ of lameness is seen below the hock and stifle (Baxter and Stashak, 2011). The investigations of Ramdy (1997), Oliver et al., (1997), Kane et al., (2000), Keegan et al., (2000) and Baxter (2011) have shown that lameness is the most important disease and a major reason for training days being lost and wastage in horse industry. In the present scenario, equine lameness is emerging branch in India and there are very few studies which was conducted on incidence of lameness in 
horses. So, looking to the facts, the study was designed to know epidemiological status of lameness in horses.

\section{Materials and Methods}

To know epidemiological status of lameness in horses, signalment and clinical details of three years cases reported at Veterinary Clinical Complex, College of Veterinary Science \& A. H., Junagadh Agricultural University, Junagadh were analyzed which included retrospective data of last three years (April, 2017 - March, 2020).

For signalment, age, sex, breed and season wise incidences of lameness were recorded while clinical details like anatomical location of site of lameness, limb/s involved and diagnosis of different affections causing lameness in horses were analyzed to know epidemiological status of lameness.

\section{Results and Discussion}

During the last three years (April, 2017 March, 2020), total 2004 cases of horses were reported at Veterinary Clinical Complex, College of Veterinary Science \& A. H., Junagadh Agricultural University, Junagadhin which 1078 (53.79\%) cases were affected with different types of surgical affections.

Out of which, 206 (10.27\%) animals were showing lameness due to various conditions. Similarly, Mistry et al., (2012) carried out a retrospective study of equine lameness during ten years (2000-2010) in which total 796 equine cases were reported, wherein 302 cases $(37.93 \%)$ of surgical affections and out of them, 176 cases $(22.11 \%)$ were affected with various lameness aliments. Himani (2018) recorded total of 117 horses with the clinical signs of lameness during one-year period.

\section{Age}

In the present study, the highest incidence was recorded in the age group of less than 5 years $(100 / 206,48.54 \%)$, followed by 6 to 10 years $(73 / 206,35.44 \%), 11$ to 15 years $(27 / 206,13.11 \%)$ and more than 15 years $(6 / 206,2.91 \%)$ (Table 1). During this study, a higher incidence of lameness was observed in the young age group which might be due to the adolescent nature of animals and initiation of training in early stages.

Similarly, Varshney (1997) reported a higher incidence of lameness in yearlings while Cogger et al., (2008) and Mistry et al., (2012) reported a high incidence of lameness in a younger age group (less than 2 years) while Naeini and Niak (2005) reported more cases of six to eight years old horses (32.14\%) affected with lameness, followed by four to six-years (22.62\%), eight to ten-years (19.05\%), two to four-years $(16.67 \%)$ and more than ten-years $(9.52 \%)$ of horses.

\section{Gender}

The incidence of lameness was found higher in females $(162 / 206,78.65 \%)$ as compared to males (44/206, 21.35\%) during this study (Table 2) which might be due to population differences prevalent in this region because majority of owners kept female animals for breeding purpose. These findings corroborate with earlier studies by Himani et al., (2019), Koshiya (2018), Mistry et al., (2012) and Varshney (1997) also reported a high incidence of lameness in females. Whereas Cogger et al., (2008) found no difference in the relative occurrence of lameness between male and female groups in general.

\section{Breed}

Breed wise distribution of the affected horses showed a higher incidence of lameness in 
Kathiawari breed $(91 / 206,44.17 \%)$ followed by Non-descript breed (69/206, 33.49\%), Marwari breed (40/206, 19.41\%), Thoroughbred $(3 / 206,1.45 \%)$ and Sindhi breed $(3 / 206,1.45 \%)$ (Table 3). A higher incidence of lameness in Kathiawari breed was reported in the present study which might be due to a higher population of Kathiawari breed in its native tractof saurashtra regionof Gujarat state, India. Similarly, Koshiya
(2018) also reported $57.14 \%$ of Kathiyawari horses affected with laminitis during his study. Mistry et al., (2012) found majority cases of the non-descript breed (156) followed by Marwadi (16), Kathiawari (3) and Thoroughbred (1). Whereas, Naeini and Niak (2005) examined horses for lameness and reported high incidence in show jumping horses of Thoroughbred, Turkmen, Arabian, Mixed, Caspian, Kord or Russian breed.

Table.1 Age-wise distribution of cases showing lameness in horses

\begin{tabular}{|l|c|c|c|c|}
\hline \multirow{2}{*}{} & \multicolumn{4}{|c|}{ Age groups (Years) } \\
\cline { 2 - 5 } & $\leq \mathbf{5}$ & $\mathbf{6 - 1 0}$ & $\mathbf{1 1 - 1 5}$ & $>\mathbf{1 5}$ \\
\hline No. of cases & 100 & 73 & 27 & 6 \\
\hline Percentage (\%) & $48.55 \%$ & $35.43 \%$ & $13.11 \%$ & $2.91 \%$ \\
\hline
\end{tabular}

Table.2 Sex wise distribution of cases showing lameness in horses

\begin{tabular}{|l|c|c|}
\hline & Male & Female \\
\hline No. of cases & 44 & 162 \\
\hline Percentage $(\boldsymbol{\%})$ & 21.35 & 78.65 \\
\hline
\end{tabular}

Table.3 Breed wise distribution of cases showing lameness in horses

\begin{tabular}{|l|c|c|c|c|c|}
\hline & Kathiawari & Marwari & Non-descript & Thoroughbred & Sindhi \\
\hline No. of cases & 91 & 40 & 69 & 03 & 03 \\
\hline Percentage (\%) & 44.17 & 19.41 & 33.49 & 1.45 & 1.45 \\
\hline
\end{tabular}

Table.4 Month and season wise distribution of cases reported during the study

\begin{tabular}{|l|c|c|c|}
\hline Months & No. of cases & Percentage & $\begin{array}{c}\text { Season wise incidence } \\
\text { (percentage) }\end{array}$ \\
\hline March & 31 & 15.04 & $\begin{array}{c}\text { Summer } \\
99(48.05 \%)\end{array}$ \\
\hline April & 23 & 11.17 & \\
\hline May & 25 & 12.14 & Winter \\
\hline June & 20 & 9.71 & $59(28.65 \%)$ \\
\hline November & 13 & 6.31 & \\
\hline December & 10 & 4.85 & Monsoon \\
\hline January & 18 & 8.74 & $48(23.30 \%)$ \\
\hline February & 18 & 8.74 & \\
\hline July & 14 & 6.80 & \\
\hline August & 19 & 9.22 & 4.37 \\
\hline September & 09 & 2.91 & \\
\hline October & 06 & & \\
\hline
\end{tabular}


Table.5 Affected body regions and limb/s wise distribution of cases showing lameness

\begin{tabular}{|c|c|c|c|c|c|c|c|c|c|}
\hline \multirow{3}{*}{$\begin{array}{l}\text { Affected body } \\
\text { region }\end{array}$} & \multicolumn{4}{|c|}{ Unilateral } & \multirow{2}{*}{\multicolumn{2}{|c|}{ Bilateral }} & \multirow{3}{*}{$\begin{array}{c}\text { All } \\
\operatorname{limbs}\end{array}$} & \multirow{3}{*}{$\begin{array}{l}\text { No. of } \\
\text { cases }\end{array}$} & \multirow[t]{3}{*}{ Percent } \\
\hline & \multicolumn{2}{|c|}{ Forelimb } & \multicolumn{2}{|c|}{ Hindlimb } & & & & & \\
\hline & Left & Right & Left & Right & $\begin{array}{l}\text { Fore } \\
\text { limbs }\end{array}$ & $\begin{array}{l}\text { Hind } \\
\text { limbs }\end{array}$ & & & \\
\hline Cannon & 7 & 9 & 5 & 2 & 1 & 1 & - & 25 & 12.14 \\
\hline Elbow & 3 & 2 & - & - & - & - & - & 5 & 2.42 \\
\hline Fetlock & 6 & 8 & 3 & 4 & 10 & 4 & 1 & 36 & 17.48 \\
\hline Forearm & 1 & 1 & - & - & - & - & - & 2 & 0.97 \\
\hline Gaskin & - & - & 6 & 1 & - & 1 & - & 8 & 3.88 \\
\hline Hip & - & - & 7 & 4 & - & 2 & - & 13 & 6.31 \\
\hline Hock & - & - & 6 & 4 & - & 5 & - & 15 & 7.28 \\
\hline Hoof & 6 & 5 & 5 & 3 & 27 & 2 & 10 & 58 & 28.15 \\
\hline Knee & 4 & 4 & - & - & 2 & - & - & 10 & 4.85 \\
\hline Pastern & 5 & 1 & 1 & - & - & - & - & 7 & 3.40 \\
\hline Shoulder & 3 & 7 & - & - & 1 & - & - & 11 & 5.34 \\
\hline Stifle & - & - & 8 & 1 & - & 1 & - & 10 & 4.85 \\
\hline Whole limb & - & - & 2 & 1 & 1 & 2 & - & 6 & 2.91 \\
\hline Total & 35 & 37 & 43 & 20 & 42 & 18 & 11 & 206 & 100 \\
\hline Percentage & 16.99 & 18.00 & 20.87 & 9.70 & 20.38 & 8.73 & 5.33 & 100 & 100 \\
\hline
\end{tabular}

Table.6 Condition wise distribution of cases showing lameness

\begin{tabular}{|c|l|c|c|l|c|}
\hline Sr. No. & Diagnosis & No. of cases $(\mathbf{\%})$ & Sr. No. & Diagnosis & No. of cases $(\boldsymbol{\%})$ \\
\hline $\mathbf{1 .}$ & Arthritis & $14(6.79)$ & 21. & Hoof wall crack & $1(0.48)$ \\
\hline $\mathbf{2 .}$ & Bog spavin & $5(2.42)$ & 22. & Laminitis & $34(16.50)$ \\
\hline $\mathbf{3 .}$ & Bone spavin & $2(0.97)$ & 23. & Myositis & $42(20.38)$ \\
\hline $\mathbf{4 .}$ & Bucked shin & $2(0.97)$ & 24. & Navicular disease & $1(0.48)$ \\
\hline $\mathbf{5 .}$ & Bursitis & $1(1.94)$ & 25. & Osselets & $5(2.42)$ \\
\hline $\mathbf{6 .}$ & Capped elbow & $10(4.85)$ & 27. & Quittor & $1(0.48)$ \\
\hline $\mathbf{7 .}$ & Chronic laminitis & $4(1.94)$ & 28. & Ring bone & $4(1.94)$ \\
\hline $\mathbf{8 .}$ & Conformational defect & $4(1.94)$ & 29. & Radial nerve paralysis & $7(3.39)$ \\
\hline $\mathbf{9 .}$ & Coxitis & $2(0.97)$ & 30. & SDFT \& DDFT rupture & $1(0.48)$ \\
\hline $\mathbf{1 0 .}$ & Fracture of fibula & $1(0.48)$ & 31. & Sesamoiditis & $1(0.48)$ \\
\hline $\mathbf{1 1 .}$ & Fracture of hip & $3(1.45)$ & 32. & Splints & $1(0.48)$ \\
\hline $\mathbf{1 2 .}$ & Fracture of humerus & $7(3.39)$ & 33. & Sprain & $2(0.97)$ \\
\hline $\mathbf{1 3 .}$ & Fracture of metacarpal & $4(1.94)$ & 34. & Strain & $1(0.48)$ \\
\hline $\mathbf{1 4}$. & Fracture of metatarsal & $2(0.97)$ & 35. & String halt & $1(0.48)$ \\
\hline $\mathbf{1 5 .}$ & Fracture of radius & $1(0.48)$ & 36. & Subsolar abscess & $1(0.48)$ \\
\hline $\mathbf{1 6 .}$ & Fracture of sesamoid bone & $3(1.45)$ & 37. & Tendinitis & $8(3.88)$ \\
\hline $\mathbf{1 7 .}$ & Fracture of tibia & $1(0.48)$ & 38. & Tenosynovitis & $14(6.79)$ \\
\hline $\mathbf{1 8 .}$ & Fracture of ulna & $3(1.45)$ & 39. & Thrush & $3(1.45)$ \\
\hline $\mathbf{1 9}$ & Gonitis & $4(1.94)$ & & & \\
\hline $\mathbf{2 0 .}$ & Hip dislocation & & & \\
\hline
\end{tabular}




\section{Season}

In study, season-wise analysis suggested the highest incidence of lameness during the summer season $(99 / 206,48.05 \%)$, followed by winter season $(59 / 206,28.65 \%)$ and monsoon season $(48 / 206,23.30 \%)$ (Table 4). While month wise distribution was suggestive of more cases during period of March to June months. High incidences of lameness during the summer season was possibly due to overexcursion of horses during wedding ceremonies organized mainly during the summer season. Likewise, Mistry et al., (2012) reported high incidences of lameness in the summer season as compared to monsoon and winter. Kane et al., (2000) also reported a higher incidence of lameness in the summer season.

\section{Anatomical location}

Highest numbers of lesions were diagnosed in hoof region with $(58 / 206,28.16 \%)$ followed by fetlock region $(36 / 206,17.47 \%)$, cannon region $(25 / 206,12.13 \%)$, hock region (15/206, 7.28\%), hip region $(13 / 206,6.31 \%)$, shoulder region $(11 / 206,5.33 \%)$, knee region and stifle region $(10 / 206,4.85 \%)$, gaskin region $(8 / 206,3.88 \%)$, pastern region $(7 / 206$, $3.39 \%)$, full limb involvement (6/206, $2.91 \%)$, elbow $(5 / 206,2.42 \%)$ and forearm region $(2 / 206,0.97 \%)$ (Table 5). Hoof affections was very commonly noticed due to its anatomical location, weight bearing and possibility of wearing \& tearing during work. Similarly, Himani (2018) reported highest numbers of lesions in hoof region $(25.81 \%)$ followed by hock joint region (22.58\%), fetlock joint region $(21.77 \%)$, pastern joint region $(13.71 \%)$, metacarpal/metatarsal region $(8.87 \%)$ and carpal joint region (7.26\%). Mistry et al., (2012) also reported that the incidence of foot affections was highest followed by hock and fetlock joint disorders.

\section{Limb/s involved}

In present study, the involvement of left hindlimb was reported highest in 43 cases (20.87\%) followed by right forelimb (18\%), left forelimb (16.99\%) and right hindlimb $(9.70 \%)$. Likewise, in bilaterally affected limbs, forelimbs were recorded in 42 cases (20.38\%) followed by hind limbs (18/206, $8.73 \%)$, while 11 cases $(5.33 \%)$ were reported with the involvement of all limbs (Table 5). The highest involvement of hindlimbs might be due to more use of horses during ceremonies for dancing purpose in which horses has to stand on hind limbs for various dancing styles. Similarly, Mistry et al., (2012) recorded highest number of cases with involvement of unilateral hindlimb $(35.79 \%)$ followed by unilateral forelimb $(30.11 \%)$. Whereas, Baxterand Stashak (2011), Varshney (1997) and Cogger et al., (2008) reported a high incidence of forelimb affections which might be due to increased weight bearing on the forelimbs (60-65\%) and shock of landing that the forelimbs absorb during movement.

\section{Various affections causing lameness}

Condition/affection wise analysis of all cases suggested the highest incidence of myositis $(42 / 206,20.38 \%)$ followed by laminitis $(34 / 206,16.50 \%)$, arthritis and tenosynovitis (14/206, 6.79\%), chronic laminitis (10/206, $4.85 \%)$, tendinitis $(8 / 206,3.88)$, ring bones and fracture of metacarpal bone (7/206, $3.39 \%)$, bog spavin and osselets (5/206, $2.42 \%$ ), while 4 cases $(1.94 \%)$ of each affection like bursitis, coxitis, fracture of the metatarsal, conformational defect, hip dislocation and quittor. 3 cases $(1.45 \%)$ of each affection like fracture of tibia, fracture of the humerus, gonitis and thrush, 2 cases $(0.97 \%)$ of each bone spavin, bucked shin, fracture of fibula, fracture of radius and sprain, lastly one case $(0.48 \%)$ of each capped 
elbow, fracture of hip bone, fracture of a sesamoid bone, fracture of ulna, hoof wall crack, navicular disease, pedal osteitis, radial nerve paralysis, SDFT \& DDFT rupture, sesamoiditis, splints, strain, stringhalt and subsolar abscess (Table 6). Similarly, Himani et al., (2019) diagnosed the highest incidence of hock osteoarthritis with 11 cases followed by laminitis and high ringbone (9), soft tissue swelling or calcification (8), periosteal reaction and proximal sesamoiditis (7), osselets and fracture of splint bone (6), carpal osteoarthritis and reduced joint space or joint effusion (5), metatarsal bone lysis (4), hoof fracture (3), low ringbone and bone spavin (3), subsolar abscess and dislocation of pastern (2), while one case of each white line disease, navicular disease, bilateral dislocation of coffin joint, fracture of first phalanx, cyst in distal metatarsal, epiphysitis, bone chip and cyst in $3^{\text {rd }}$ row of tarsal. Mistry et al., (2012) also reported wounds (31, $17.62 \%)$, laminitis $(23,13.08 \%)$, arthritis $(20$, $11.36 \%)$, fracture $(19,10.79 \%)$, tendon or ligaments disorder $(17,9.65 \%)$, luxation $(8$, $4.54 \%)$, congenital defect $(5,2.84 \%)$, hoof affections (3, 1.70\%) and other conditions (50, 28.40\%). Sadan et al., (2017) found most prevalent affections in donkeys were high and low ringbone $(29.35 \%)$ and hoof abscess $(9.78 \%)$ followed by traumatic arthritis of the fetlock $(6.52 \%)$, suspensory ligament desmitis $(5.43 \%)$, fracture of first phalanx $(5.43 \%)$, fracture of second phalanx $(4.35 \%)$, side bone $(3.26 \%)$ whereas, fracture of metacarpal bone (1.09\%), sesamoiditis (1.09\%) and flexural deformities $(1.09 \%)$ represented the lowest prevalent affections.

In conclusion the clinical epidemiology of lameness in horses during last the three years (April, 2017- March, 2020) revealed that young horses below 5 years age were more commonly affected as compared to 6 - 10 years; 11 - 15 years and more than 15 years of age groups. While gender wise females were reported to be more affected with lameness than males. The incidences of lameness were high in Kathiawari as well as Non-descript breed of horses than Marwari, Thoroughbred and Sindhi breed. Highest incidences of lameness were observed during summer season from March to June months and which was higher in left hindlimb followed by right forelimb, left forelimb and right hind limb while comparison of bilateral limb involvement showed higher rate of lameness in forelimbs than that of hindlimbs. Diagnosed condition wise analysis of all cases suggested the highest incidence of myositis followed by laminitis and arthritis were more frequently reported in horses during the study.

\section{Acknowledgement}

The authors express profound of gratitude to the Dean, Collage of Veterinary Science and Animal Husbandry, Junagadh for the facilities provided. Senior author is thankful to major advisor and members of advisory committee for their constant guidance and help to carry out this research work smoothly.

\section{References}

Baxter, G. M. 2011. Fundamentals of lameness diagnosis. In: Baxter, G.M. (Ed.), Manual of Equine Lameness, First ed. Wiley-Blackwell, West Sussex, UK., pp. 65-82.

Baxter, G. M. and Stashak, T. S. 2011. Examination for lameness.In: Baxter, G. M. (Ed.), Adams and Stashak's lameness in horses, Six ed. WileyBlackwell, West Sussex, UK., pp.109206.

Cogger, N., Evans, D. L., Hodgson, D. R., Reid, S. W. and Perkins, N. 2008. Incidence rate of musculoskeletal injuries and determinants of time to recovery in young Australian Thoroughbred racehorses. Aust. Vet. 


\section{J.86(12),473-480.}

Hammarberg, M., Egenvall, A., Pfau, T. and Rhodin, M. 2016. Rater agreement of visual lameness assessment in horses during lungeing. Equine Vet. J. 48(1), $78-82$.

Himani. 2018. Evaluation of diagnostic nerve blocks and radiography for the localization of lameness in equine, Punjab, India. M. V. Sc. Thesis, Guru Angad Dev Veterinary and Animal sciences University, Ludhiana, India.

Himani., Kumar, A., Anand, A., Singh, N., Uppal, V. and Mohindroo, J. 2019. Clinical occurrence and radiographic diagnosis of distal limb lameness in equine. Indian J. Anim. Sci.89(1), 1524.

Kane, A.J., Traub-Dargatz, J., Losinger, W.C. and Gather, L.P. 2000. The occurrence and causes of lameness and laminitis in the U. S. horse population. Proc. Ann. Cony. AAEP. 46, 277-80.

Keegan, K. G., Wilson, D. A., Smith,B. K. and Wilson, D. J. 2000. Changes in kinematic variables observed during pressure induced fore limb lameness in adult horses trotting on a treadmill. Amer. J. Vet. Res.61, 612-619.

Koshiya, A. H. 2018. Clinical studies in laminitic horses based on radiographical, haemato-biochemical and oxidative stress assessment, Gujarat, India. M. V. Sc. Thesis, Junagadh Agricultural University, Junagadh, India.
Mistry, J. N., Nirurkar, S. S., Patel, P. B., Chaudhary, S. R. and Dabas, V. S. 2012. Equine Lameness - A Retrospective Study of 176 Animals. IntasPolivet. 13(2), 187-191.

Naeini, A. T. and Niak, B. T. 2005. Field study of the prevalence of lameness in horses in three provinces of Iran. Pak. Vet. J. 25(3), 140-142.

Oliver, A., Nurton, J. P. and Guthrie, A. J.1997. An epizoological study of wastage in Thoroughbred race horses in Gouteng South Africa. J. South Africa. Vet. Assoc. 68, 125-129.

Ramdy, D. W.1997. Prospective evaluation of forelimb flexion tests in practice: clinical response, radiographic correlation and predictive value for future lameness. Proc. Ann. Conv. Amer. Assoc. Eq. Prac. 43, 116-120.

Sadan, M. A., Abdel, H. A. A. A., Metwally, A. A. and Soliman, A. S. 2017. Clinico radiographic studies on the prevalent distal limb affections in working equine at luxor city. J. Adv. Vet. Anim. Res. 7(1), 24-32.

Varshney, J. P. 1997. Equine lameness: A retrospective study. Indian J. Vet. Surg. 18(1), 27-28.

Whitton, C. 2010. Lameness in horses: Development of orthopedic disease. In: Kahn, C. M. and Line, S. (Ed.), The Merck Veterinary Manual, Ten ed. Merk \& Co., N. J., USA., pp. 997-1046.

\section{How to cite this article:}

Tank, D. P., R. H. Bhatt, V. D. Dodia, J. V. Vadalia and Padaliya, N. R. 2020. Epidemiological Status of Lameness in horses: A Retrospective Study. Int.J.Curr.Microbiol.App.Sci. 9(09): 681687. doi: https://doi.org/10.20546/ijcmas.2020.909.086 